JSACE 4/17

Study of Consequent Damage of Metal Pivotal Structure on Maintenance in Polluted Surroundings

Received 2016/08/18

Accepted after revision 2016/11/07

\section{Study of Consequent Damage of Metal Pivotal Structure on Maintenance in Polluted Surroundings}

\author{
Jūratė Mockienè ${ }^{*}$, Valerijus Keras, Gintaris Cinelis
}

Department of Building Structures, Kaunas University of Technology

Studentu str.48, LT- 51367 Kaunas, Lithuania

*Corresponding author: jurate.mockiene@ktu.lt

$\Gamma$

http://dx.doi.org/10.5755/j01.sace.16.7.16080

\section{Rudiments of author's position}

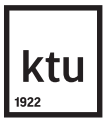

Journal of Sustainable Architecture and Civil Engineering Vol. 4 / No. 17 / 2016 pp. $68-76$

DOI 10.5755/j01.sace.17.4.16080 (c) Kaunas University of Technology
The main goal of this paper is to reveal a level of environment pollution around specific structures exploited in the open air concomitant processes and after-effects characteristic to their exploitation. Rudiments and basic point of this study are:

1 Consolidation and special analysis of information accumulated over a long time on natural concentration of aggressive pollutants in the environment affecting the objects in the unfavourable environment.

2 Experimental research of standard mechanical characteristics specific to structural material after structure exploitation (residual strength, etc.)

3 Computer-based imitation modelling of primary destruction process and discussion of its possible consequences.

The object of the study is complex as it includes pollution data in the aggressive environment enveloping characteristic building structures and its destructive impact on endurance of these structures. For instance, peculiar high-altitude clouds and their influence on the destruction of various structures such as masts, towers, supports of electro power lines, etc. is presented in the article. Data about specific pollution and aggressive environment around the objects in high volume traffic 
routes and traffic jams, their destructive influence and possible concomitant effects occurring in the construction of bridges and viaducts are revealed simultaneously. Relevance of this study lies in today's regulations. Underestimation of the above-mentioned modern aggressive factor as it becomes incompatible with a current tendency to expand sustainable development (separately a resource saving construction) is clarified.

Its significance is determined by a demand for systematic accumulation of versatile factual information about the extent of natural losses in this complicated situation. Practical engineering needs also stimulate the tendency towards complexity. A serious concern and the abundance of scattered efforts for primary elucidation and quantitative evaluation of water, air, soil, food, flora, and fauna pollution are observed. Unfortunately, the collected data is dispersed in various resources and is vaguely associated with social, economic and especially engineering losses. This is an obvious obstacle to achieve desirable practical goals. This deficiency has to be gradually filled up.

This article is expected to serve as aspiration to reach one of the sub-goals from a wide set of goals in sustainable development. A serious concern is continuously declared and numerous efforts are undertaken in order to properly reveal and estimate the extent of water, air, soil, residence, food, flora, and fauna pollution, etc. quantitatively. Nevertheless, all the data collected is scattered and not related properly at time with problem of structure endurance.

Thus, the data has limited value or is insufficient for modern engineering theory and practice development intended to vital resources and material resources saving. This drawback is sensible to be gradually filled up by systematization of store knowledge and supplementary information. Taken alone, building sphere and corresponding losses generated by environment pollution are to be discussed.

Accidents in structures and related objects have caused structure damage or totally destroyed them at last. This phenomenon has been continuously observed in various regions of the world. The above mentioned accidents occur in various structures of steel, reinforced concrete, wood and other materials. Consequently, discrepancy between environment pollution and endurance of building structures is a relevant problem in contemporary world and has to be considered in versatile perspective.

Contemporary fore going stimulators (predecessors) stimulating construction discretization can be revealed as various forms of air pollution causing construction environment aggression in Nature exploitation. It is relevant and sensible to note that a certain group of structures is exploited in the open air without a special protection. Various acidic pollutants can be likewise hazardous to steel constructions and equipment. Bearing structures of bridges, various technological equipment, towers, masts, supports of power lines, etc. are among them. Their working life, fatigue and cracking have not been sufficiently studied. Open air is undoubtedly polluted environment suitable to hasten corrosion in steel, concrete or wood. This is particularly noticeable for hardened steel.

Unfortunately, a significant complex of data characteristic to the specific corrosion process and ensuring a sufficient description of kinetic of various sub-processes is absent now. This lack of information is a serious obstacle to achieve optimal design, to assure preventive measures in exploitation, i.e. safe and economically rational preventive method against deterioration and cracking, also for other effective solutions. Consequently, this obstacle is to be gradually eliminated.

Quite widely are discussed their location into air (Paulauskienè et al. 2011 etc), soil (Butkus et al. 2004; Stravinskienè 2011 etc), rivers and seas (Šukyte et al. 2002 etc) etc. Excerpt of some quite characteristic to exploitation spell of rather early wrecked structures data are presented in Tables 1,2,3. 


\section{Table 1}

Excerpt a concentration of sulphur pollution in South Lithuania (Šopauskienè, Jasinevičienè 2004)

\section{Table 2}

Excerpt of data a $\mathrm{SO}_{2}$ pollution into South West Lithuanian area (Sirakov et al. 1989)

\section{Table 3}

Excerpt a concentration of sulphur pollution in South Lithuania (Šopauskienè, Jasinevičienè 2004)

\begin{tabular}{c|c|c}
\multicolumn{1}{c|}{ Years } & Average annual & Extremes \\
\hline 1981 & 7.8 & $3.6 \ldots 14.2$ \\
\hline 1982 & 8.3 & $3.8 \ldots 25.4$ \\
\hline 1983 & 9.3 & $3.4 \ldots 19.4$ \\
\hline 1984 & 8.0 & $5.7 \ldots 16.2$ \\
\hline
\end{tabular}

\begin{tabular}{l|c|c}
\hline \multicolumn{1}{|c|}{ Years } & $\begin{array}{c}\mathrm{SO}_{2} \\
\left(\mathrm{c} \mathrm{m} \mathrm{kg} / \mathrm{m}^{3}\right)\end{array}$ & $\begin{array}{c}\mathrm{sO}_{4}^{2-} \\
\left(\mathrm{c} \mathrm{m} \mathrm{kg} / \mathrm{m}^{3}\right)\end{array}$ \\
\hline 01.82 & 11.54 & 13.06 \\
\hline 01.83 & 5.14 & 5.09 \\
\hline 01.84 & 16.68 & 10.55 \\
\hline 01.85 & 18.54 & 17.73 \\
\hline 02.11 .85 & 9.52 & 9.3 \\
\hline
\end{tabular}

\begin{tabular}{l|c}
\hline Žuvintas & 4.2 \\
\hline Preila & 4.1 \\
\hline Molètai & 4.3 \\
\hline The European (ex-USSR) part of Russia & $1.65-4.0$ \\
\hline Southern Sweden & $3.4-4.8$ \\
\hline Northern Sweden & 2.0 \\
\hline Southern Norway & $6.9-10$ \\
\hline Northern Norway & $0.5-0.8$ \\
\hline Eastern Hungary & 7.0 \\
\hline West Germany & $3.9-8.0$ \\
\hline
\end{tabular}

Tendencies and requirements of optimal design promote the increased focus on structure rational viability in polluted environment (Agenda and other). This aim could be achieved by complex optimisation. This condition is quite significant if a structure is planned to be exploited under the insufficiently known conditions, e.g. in aggressively polluted environment. These conditions cannot be ignored in searching optimal solutions ensuring rational structure viability in various aspects. The real behaviour of optimised buildings and structures defining their rationality is the function of conditions occurring during structure exploitation (Keras et al 2005; Kudzys, Juocevičius 2005; Keras, Mockienè 2007,2009). In most cases it is a consequence of complicated events and processes.

It directly refers to buildings and structures exploited in polluted environment for a long time, i.e. high-altitude towers and masts installed in the area of chemically aggressive industrial pollutants, nearby industrial zones and directly in them. This information can be significant in solution multipurpose optimisation in designing high-altitude objects.
There are also other contaminants besides the sulphur compounds that are dangerous to structural steel. Sulphur acid is probably the most dangerous material. Therefore some part of data about the pollution extent, forms and concentration of sulphur pollution is provided as examples. (Measurements fixed during the taminants combinations change comprising big sets of information which are the subject for analysis and discussion in the dedicated literature.)

At the time already is some actual data about pollute emissions, revealed in industry (Paulauskas, Klimas 2005; Vyzienè, Girgždys 2009), traffic (Lippa, Špakauskas 2002; Byčenkienè, Girgždienè 2006; Vaitiekūnas, Banaitytè 2007), agriculture (Butkus et al. 2004), cattle-breeding (Kavolèlis, Bakutis 2004), forestry (Ozolinčius 2005; Gimbutaite, Venckus 2008).
Processes of structure corrosion provoked by contaminants 
Abundant data on aggressive pollutants in such zones was described and partially summarised in earlier publications and the fore presented part of the article.

A part of this data is compiled by long-term natural observations peculiar for real structure-related events, processes and consequences. The accumulated data shows various details and facts of buildings and structures behaviour. It is appropriate to generalise the information and relate it to the data of viability change and the development of construction damage revealing practical significance and impact of their combinations. It would contribute to solving optimisation issues.

Some peculiar phases can be recorded in the behaviour of high-altitude steel structures and constructions during their long-term exploitation under aggressive conditions. The major part of steel corrosion factors occurs in the surface layer of a structure element. It includes painting defects or other corrosion-sensitive metal surfaces.

Deterioration formations are noticeable in metal surface contacting with polluted environment that includes air and humidity. They include dotted corrosive areas, which are microscopic at the start. Steel transforms from solid state into powdery condition in such dotted areas. The major part of steel as a material component reacting to moisture, air and pollutants turns into surface micro craters filled by accumulation of powdery corrosion products. The accumulated powder absorbs and stores environment moisture and polluted air, so harmful and aggressive for the metal. These are the favourable conditions for corrosion to develop and deepen the crater. Initially, craters were similar to dotted areas. Later on they develop into adjacent surface areas. Eventually, they form entire surface corrosion. Such formations create concentric areas, gullies and grooves of corroded steel. Moreover, dotted corrosion formations, craters on the surface cause accompanying effect - closed metal corrosion. It is a process of micro cavities and formations occurring under the metal surface unaffected by surface corrosion. They can form closed gully cavities among dotted corrosion areas and craters.

Corrosion development under the metal surface layer might be more hazardous from the point of view of metal deterioration. Its prevention by coating metal with anti-corrosive layers is ineffective. This process is more complicated and causes significant consequences. It occurs simultaneously as the development of primary deterioration craters.

This process evolves while metal surface layer is still intact, it damages metal layer which is not comparatively deep between dotted corrosion areas. Products as the consequence of closed under-surface corrosion processes obtain higher volume than the initial volume of non-corroded steel components. Thus, development forces occurring and affecting under-surface cavities are high and exceed cohesion forces of material (steel) components. Expansion forces tear surface layer area above gully up even if dotted corrosion formations or other damage are not yet formed. Such torn surface layer is rough with micro, sub micro concaves, sharpness and protrusions. The new surface area after corrosive tear is much larger than relatively even surface area of a structure element prior to corrosive damage. It means that the new area is expanded regarding steel and polluted environment; it creates favourable conditions for intensive corrosion development. Corrosion development gradually changes distribution of surface stresses and strains.

Dotted deterioration areas, micro damage and other assumptions cause the accompanying effect, i.e. concentration of stresses and deformations. Any concentration of stresses and deformations supplement the initial impact of roughness of technological processing and other micro unevenesses of structure element surfaces on surface stress distribution.

Craters, gullies, cracks and fissures occur in structural steel element under the effect of polluted environment and corrosion; they influence dispersion of steel macro characteristics. Defect development starts to significantly impact the local and nominal strength data of steel, its yield, strength and deformation rates. Corrosion start and its development are caused by surface processing irregularities or relatively low quality of technological processing, i.e. defects occurring in shrinkage of welding seams as polluted moisture is condensed there. Various chemically active steel admix- 
tures also have similar corrosive effect. Technical steel is a combination of various admixtures and additives, though their percentage in a general composition is relatively low.

High-altitude construction masts usually are made of rolled steel profiles. Technological rolling processes leave microscopic cracks on hardened steel element surface in some places. The major changes are possible in the stress-strain state of a structure element as corrosion promoted by polluted environment together with other factors gradually change so-called surface stresses and deformations. In linear stress and deformation distribution occur micro, sub micro and local islands of stress-strain concentration as 3D stress-strain state zones, which reduce element strength reserve and increase deterioration hazard.

Fig. 1

Variation initial forms of corrosive damages

Fig. 2

An example of following evolution of corrosive damage on surfaces of metal structure into pollutes surroundings. Some characteristic samples

Fig. 3

Totally corroded superficial layer of structural element
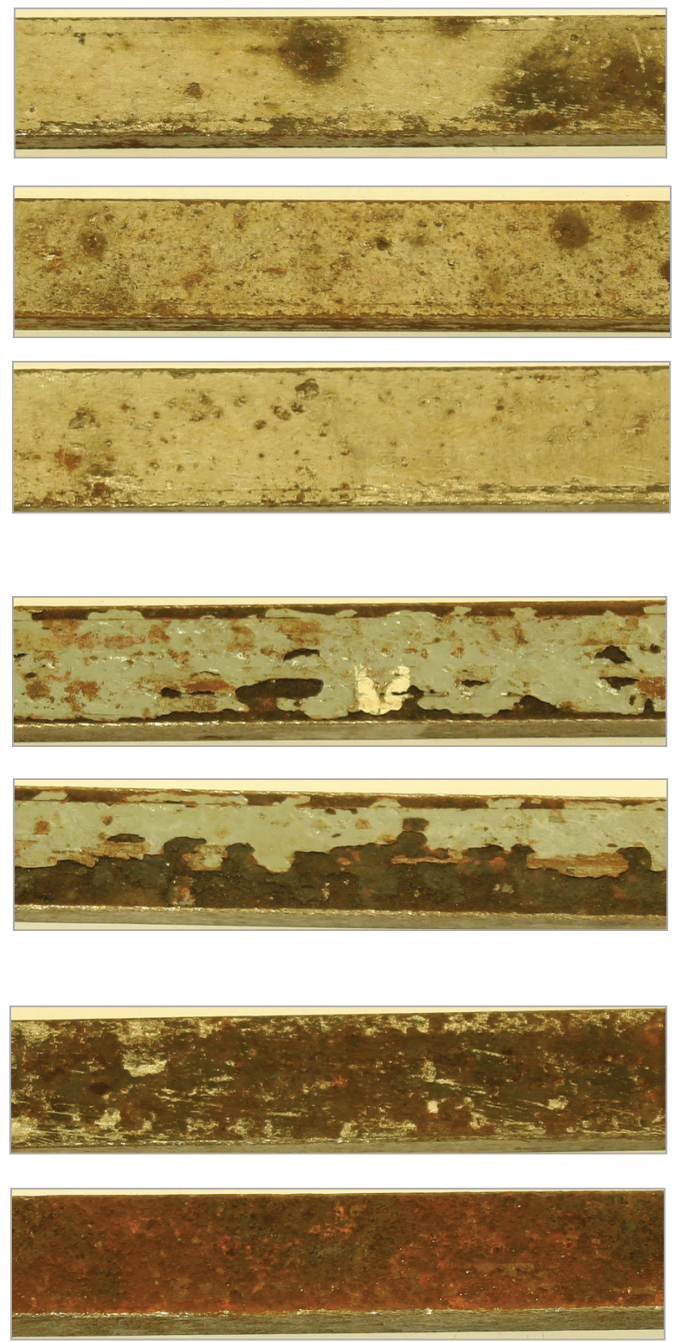

Significant deformation unevenness peculiar to stress concentration stimulate material surface layer cracking and cavity occurrence. This is secondary - mechanical - deterioration of structure elements. It is not directly dependent on environment pollution or corrosion. It is an accompanying effect, an indirect consequence of corrosion processes, function of partially changed border conditions. In turn secondary cracking increases steel structure areas for corrosion and creates conditions for development of surface corrosion. This publication presents the practical study result extracts of the main outcome of the analyzed processes.

The pictures (Fig. 1, 2, 3, 4) provide specific information on steel element damage occurring during various periods of structure exploitation. Other illustrations (Fig. 5) reflect the data on steel mechanical properties, their change and dispersion after long-term exploitation of the analyzed structures.

The first part of the practical study analyzes the most significant visible outcomes of destructive corrosive-erosive processes. Accumulated data reveal formation of gullies, their merger into specific forms of damage: local areas, damaged zones, stripes (Fig. 1, 2, 3, 4). The pictures provided below reflect specific forms of steel element damage, their arrangement and amounts.

Pictures (Fig. 1, 2, 3, 4) present the main part of the mostly occurred long-term steel corrosion examples - local zones (Fig. 1), stripes and surface caused by environment pollution (Fig. 2), total surface destruction (Fig. 3).

Aggressive environment causes steel to lose primary standard characteristics of a manufacturer. Mechanical characteristics of steel were analyzed in order to find out the possible impact of damage to structure viability. Standard tests were used to determine steel yield, strength and hardness characteristics. Test data are processed to show changes of mechanical properties after exploitation in polluted environment. 

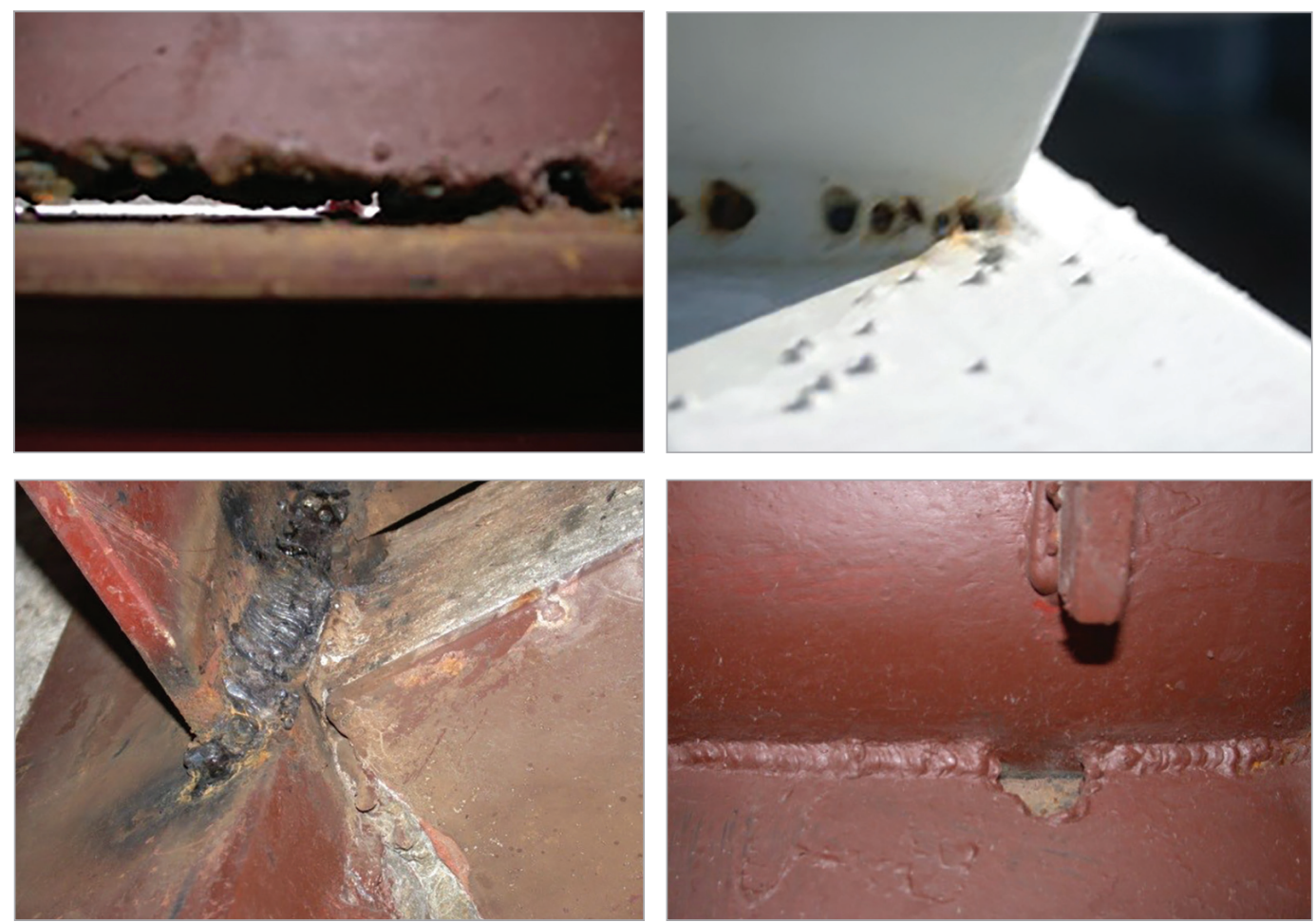

A part of indexes of mechanical properties are provided in the pictures (Fig. 5). Histograms provided in presented figures are the extracts from data sets that were gathered by examining in a general standard way the resistance of elements taken from one third of middle part of the mast. This data are the resistance properties which were obtained using tension standard form specimens to their rupture in the press. Additionally were Brinell hardness tests performed in the environment of these specimens by distracting the imprint from probable specimen rupture place. The mast under investigation has been used in open-air conditions in Lithuania near Kaunas. The mast structure was built of the cross sectional lattice, the ends of lattice elements were welded to vertical branches (stands) of the mast.

Besides observations confirmed that corrosion damages not only the mast elements, their weld seams but also the guys that hold the mast, their anchors, guy tension control devices. Proper guys tension reduce not only because of pulsating wind or changing temperature effects but also due to slips in the damaged anchors and other factors.

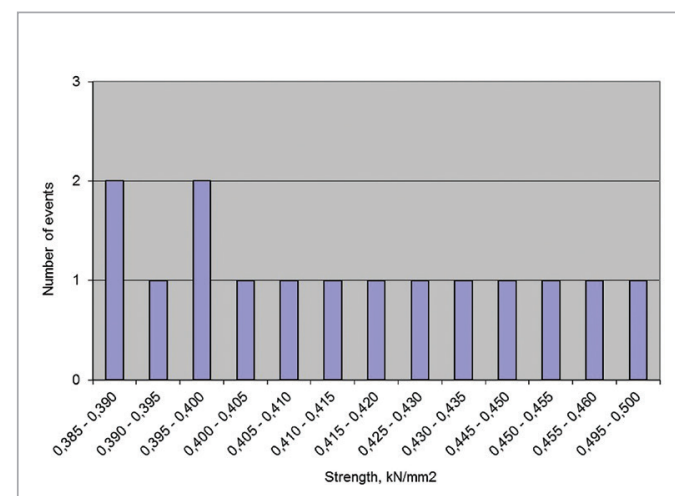

a

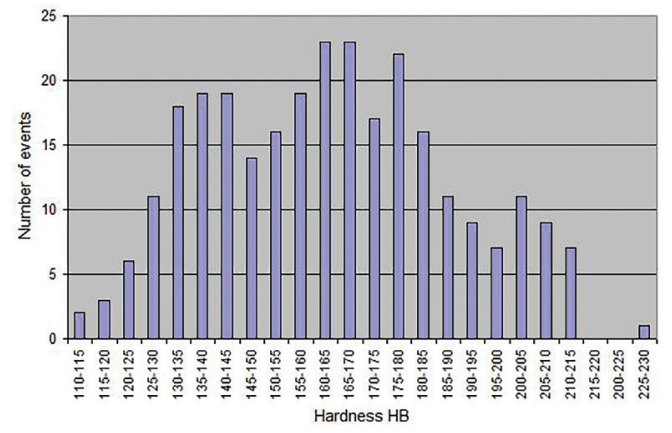

b
Fig. 4

Some characteristic damages and defects fixed during observation of various masts after a long time of their exploitation

Fig. 5

Dispersion of tested strength (test of standard specimens) (a) and hardness (b) for steel mast structure after its remove out of exploitation 
Results of the conducted tests revealed that mechanical properties of steel constructions after their exploitation periods changed significantly from the ones from manufacture standards. Steel production is certified by manufacturers. Production mechanical properties have to meet standard requirements, especially the products, which are used for crucial structures and buildings. Requirements for production quality in various countries provide $3 \%$ characteristic dispersion, e.g. strength indexes.

The given pictures prove that steel macro characteristics on tension and hardness do not meet manufacture standards after exploitation of structure in corrosion-stimulating environment. Characteristics dispersion becomes very wide. Tests for tension and hardness were cut from structure masts after exploitation period. Test data emphasizes a great dispersion of mechanical characteristics. It was 25-35\% for steel yield indexes, 28-40\% for strength characteristics (Fig. 5). Dispersion was twice higher for steel hardness characteristics which were determined for the same samples later (Fig. 5). Such differences reflect uneven arrangement and amount of damage. Hardness tests were more localized. Thus, hardness indexes are more susceptible to damage influence for mechanical properties of localized metal areas. Tension tests evaluate a more generalized (evened) steel cross-section resistance to deformation.

Authors of the paper were seeking to note that wide researches are necessary in the point of view of sustainable development and sustainable building. They could cover more cases in various countries similarly as it is happening with investigations of the pollution effects to forests, agriculture, health, etc. The research coverage can be defined as mechanical researches of building deterioration, its modelling, forecast, economical estimation, legal regulation, and possibly damage recovery. It would be appropriate to consider the research program of such like direction.

1 Many engineering systems are affected by various aggressive emissions and rather changeable polluted surroundings on the exploitation phase of systems. It causes continuously unsteady reliability and behavior of exploited structure. Unlike probability evaluation of some nature generated instability effects and the loss of initial properties or mechanical characteristics influenced by Nature the variations and their influence discussed in this paper are not appraised by probabilistic characteristics at the time being.

2 Many of metal masts and towers are exploited in the open air in the world nowadays. They have $\angle$ been built many years ago in great numbers. Some of them are left without supervision (e.g. in the Post-soviet territory). The data of Nature monitoring reveals a surroundings pollution growth at the time of exploitation of the structures of that kind. The volume of contaminants that are aggressive to building materials and structures continuously were filled up. This process has activated premature ageing of materials, deterioration of structures, loss of objects viability on the whole. Therefore various estimations should include a wider range of problems, factors, after-effects etc. in comparison with those which are taken into consideration and evaluated in high-rise structures design at present.

3 Aggressive contaminants provoke an intensification of various destructions on the surface of 3 structural element and in adjacent superficial layers. Usually corrosive damages go on spreading under the surface of element more rapidly than on its surface. So, they cannot always be observed in practice. Destructive activity of aggressive contaminants include a corrosive eating with following erosion of corroded metal, splitting of thin plates or scales, and forming of micro cracks, ravines etc.

The lack of deterministic or probabilistic data stimulate an imitation modelling of structure and its behaviour for reconstruction of its damages gradually step by step. It is a labour-consuming process. The actions of destructions and their combinations may be predicted and analyzed, graphs of possible events and their sequences may be built-up. The problem is suitable for modelling with the computer software. The results of modelling embody basic information for clearing up of undesirable situations generated by polluted surroundings, for revealing rational solutions necessary to undertake on the exploitation phase. 
An agenda for sustainable construction in Europe/ Drawn up by the Working Group for Sustainable construction with participants from the European Commission, Member States and Industry. Brussels. 2001.

Baltrènas, P., Morkūnienè, J. 2006. Investigation of particulate matter concentration in the air of Žverynas district in Vilnius, Journal of Environmental Engineering and Landscape Management 14(1): 23-30.

Baltrènas, P., Butkus, D., Oškinis, V., Vasarevičius, S., Zigmantienè, A. 2008. The environment saving. [Aplinkos apsauga.]. Vilnius. 564p. (in Lithuanian).

Bimbaitè, V.; Girgždienè, R. 2007. Evaluation of Lithuanian air quality monitoring data applying synoptically analysis, Journal of Environmental Engineering and Landscape Management 15(3): 173-181.

Byčenkienè, S., Girgždienè, R. 2006. Influence of air mass long-range transport on ozone concentration at Preila site (Lithuania). Lithuanian Journal of Physics 46(2): 251-259. https://doi.org/10.3952/ lithjphys.46213

Butkus, D., Paliulis, D., Baltrennaite, E. 2004. Sorption of heavy metals from polluted water and their migration in the system soil - tree. Journal of Environmental Engineering and Landscape Management 12 (4): 183-190.

Gimbutaite, I., Venckus, Z. 2008. Air pollution burning different kinds of wood in small power boilers, Journal of Environmental Engineering and Landscape Management 16(2): 97-103. https://doi. org/10.3846/1648-6897.2008.16.97-103

Kavolèlis, B., Bakutis, B. 2004. The Ammonia emission into cattle - breeding, [Amoniako emisija karvidèse]. Edition of the Lithuanian Academy of Sciences. Agricultural sciences. No. 1: 45-59. (in Lithuanian).

Keras, V., Valys, A., Mockienè, J. 2005. Stress - strain concentrations in high - rise structure elements and monotonic disintegration under the influence of environment contamination. Journal of Civil Engineering and Management XI (1): 49 - 55.

Keras, V., Mockienè, J. 2007. On the precritical destruction of metal (steel) structures, in Proceedings of the 9-th International Conference "Modern Building Materials, Structures and Techniques": 16-18 May 2007, Vilnius, p. [1-9].

Keras, V., Mockienè, J. 2009. Applied Mechanics into System of Harmonious Development of Mankind, in Proceedings of the 14-th International Conference "Mechanika 2009": 2-3 April 2009, Kaunas. p. 209-214.
Keras, V., Mockienè, J., Gilys, A. 2015. Problems and rudimental tends on implementation of European Union's directives on Sustainable building. Journal of sustainable architecture and civil engineering, No.1 (10): 87-98.

Kudzys, A., Juocevicius, J. 2005. Structures on Sustainable Construction Strategy. Advanced construction: materials of conference reports. Kaunas. p. 16-24.

Lippa, M., Špakauskas, V. 2002. The estimation of contamination of Lithuanian environment by auto traffic emissions, Environmental Engineering IX (3): $121-129$.

Mockiene, J., Keras, V. 2010. The loss of strength resources on exploitation of steel building structures in corrosive environment, in proceedings of the 2-th international conference "Advanced construction": 11-12 November 2010, Kaunas. p. 95-101

Ozolinčius, R. 2005. Lithuanian forests. [Lietuvos miškai]. Department of Forests, Ministry of Environment of the Lithuanian Republic. Vilnius. $211 \mathrm{p}$. (in Lithuanian).

Parkins, R.N., Beavers, J.A. 2003. Some effect of strain rate on the transgranular stress corrosion cracking of ferrite steels in dilute near - neutral $-\mathrm{pH}$ solutions, Corrosion, No. 3: 258 - 273. https://doi. org/10.5006/1.3277559

Paulauskas, L., Klimas, R. 2005. Investigation of environmental air pollution and its change assessment in Siauliai, Journal of Environmental Engineering and Landscape Management 13(1): 17-22.

Paulauskienè, T., Zabukas, V., Vaitiekūnas, P., Žukauskaitè, A., Kvedaras, V. 2011. Investigation of volatile organic compounds (VOCs) emission beyond the territory of oil terminals during different seasons, Journal of Environmental Engineering and Landscape Management 19(1): 44-52. https://doi.or $\mathrm{g} / 10.3846 / 16486897.2011 .558994$

Sirakov, D., Koralova, M., Perkauskas, D., Senuta, K., Mikelinskienè, A. 1989. Investigation of long range pollutant transport over the Baltic Sea, Coll. Sci. Pap. Atmospheric Physics, Ed. 13. Vilnius. p. 75-84.

Stravinskienè, V. 2011. Pollution of "Akmenes cementas" vicinity: alkalizing microelements in soil, composition of vegetation species and projection coverage, Journal of Environmental Engineering and Landscape Management 19(2): 130-139. https://doi.org/10.3846/16486897.2011.579449

Šopauskienè, D., Jasinevičienè, D. 2004. Time series and trends in atmospheric concentrations of
References 
sulphur and nitrogen dioxides in Lithuania in 19812001, Environmental and Chemical Physics 26(3): 100-108.

Šukytè, V.J., Rinkevičienè, E., Zelionkaitè, V. 2002. The Chemistry of Sulphur in Anoxic Zones of the Baltic Sea, Environmental Research, Engineering, and Management 3(21): 55-60.

Vaitiekūnas, P., Banaityte, R. 2007. Modelling of motor transport exhausts pollutant dispersion, Journal of Environmental Engineering and Landscape Management 15(1): 39-46.

Vyzienè, R., Girgždys, A. 2009. Investigation of aerosol number concentration in Jonava town, Journal of Environmental Engineering and Landscape Management 17(1): 51-59. https://doi. org/10.3846/1648-6897.2009.17.51-59

\section{About the authors \\ JŪRATĖ MOCKIENE் \\ Master degree, lector \\ Department of Building Structures, Kaunas University of Technology}

Main research area

Steel structures, strength, durability, destruction, rational design

\section{Address}

Kaunas University of Technology, Studentu st. 48, LT- 51367

Kaunas, Lithuania

Tel. +37068227397

E-mail: jurate.mockiene@ktu.lt

\section{VALERIJUS KERAS}

Assoc. Prof. Dr.

Department of Building Structures, Kaunas University of Technology

\section{Main research area}

Fracture mechanics, concentration of stresses and strains, durability, destruction

Address

Kaunas University of Technology, Studentu st.48, LT- 51367

Kaunas, Lithuania

\section{GINTARIS CINELIS}

Assoc. Prof. Dr.

Department of Building Structures, Kaunas University of Technology

\section{Main research area}

Computer aided architectural and structural design, CAAD systems, methods of computer graphics and quantitative analysis in design and engineering, building information modelling

\section{Address}

Kaunas University of Technology, Studentu st.48, LT- 51367

Kaunas, Lithuania

Tel. +37068798786

E-mail: gintaris.cinelis@ktu.lt 